\title{
Gender and HIV/AIDS in Eastern and Southern Africa: Rethinking Men and HIV/AIDS Mitigation Uganda and Rwanda
}

DOI: http://dx.doi.org/10.4314/rj.v3i1.7B

Roberts K. Muriisa, Mbarara University of Science and Technology

Jolly Rubagiza and Asasira Simon Rwabyoma, University of Rwanda

\begin{abstract}
This paper explores the neglected role of men in HIVIAIDS mitigation. Much of the efforts to combat HIV/AIDS widely acknowledge that the gender dimensions of the AIDS pandemic is critical both for the understanding of its impact and for successful implementation of prevention and amelioration campaigns. It is argued in the paper that for a long time there has been little effort to understand the gender roles and social pressures on men and the relationship with HIV spread. Men are represented as obstacles to efforts to fight HIV/AIDS; they resist using condoms, resist change, molesters of women and carriers of disease. The paper argues that for successful fight against HIV/AIDS, there is a need for a more balanced understanding of gender on a set of structures created by and affecting both men and women. This paper largely relies on existing literature and policy documents for analysis and augmenting men's role in HIVIAIDS mitigation in Uganda and Rwanda. The paper extensively reviews and analyses data in the existing scholarly sources to develop arguments and to make conclusions. We argue in this paper that new strategies which positively look at men's contribution are needed to fight HIV/AIDS. Based on the arguments we make we suggest that men as well as women contribute each in their rights as social categories of people during the fight against HIV/AIDS. Drawing examples from Uganda and Rwanda we look at the evolving approaches to HIV/AIDS and the positioning of men into these programs. The paper concludes that involving men and observing their positive contributions has contributed greatly to the success of these programs and ultimately to the progress in mitigating HIV/AIDS spread in Rwanda and Uganda.
\end{abstract}

Key words; Gender, HIV/AIDS, Masculinity

\section{Introduction}

HIV/AIDS gender focused interventions have been important since identification of HIV/AIDS and its relationship with heterosexuality. In recognition of gender as a driving factor in HIV/AIDS transmission, Rwanda focused on eliminating gender inequalities and increasing the capacity of women and girls to protect themselves from HIV (Rwanda Biomedical Centre, 2014). The power relations between men and women have been identified as a major facilitator of the spread of HIV. HIV/AIDS impact and spread have continued to be felt unabated. There is increasing evidence indicating that HIV/AIDS spread and impacts are 
related to gender relations. However, such studies are short of providing solutions to addressing the gender issues with regard to HIV/AIDS spread.

In particular studies such as Muriisa (2010) and UNAIDS (201a, 2013) while acknowledging the position of men in creating a situation facilitating HIV/AIDS spread, fail to look at men as solutions to the much debated gender terrain which facilitates HIV/AIDS spread. In Uganda for example, Muriisa (2010) shows that lack of economic independence and power over resource control, low social status and dependence on men for economic provisions, support and survival, restricts women's ability to discuss fidelity and to insist on condom use. In Rwanda, gender relations are well recognized for their influence in HIV/AIDS spread and the commitment to mainstream gender encompasses HIV/AIDS response (UNAIDS 2013). As already indicated, these studies provide the challenge but fail to provide solution to the problem they highlight.

Throughout these studies, it is shown that a combination of cultural and societal factors, the lack of power to negotiate for safer sex puts women and girls at higher risk of infection than men and boys. The power relations between men and women have been shown to affect the HIV/AIDS spread and impact. Mane and Aggleton (2001)acknowledge that thegender dimension of the AIDS pandemic is critical both for the understanding of its impact and the successful implementation of prevention and amelioration campaigns and also shows that men have been largely ignored. However, their study does not show how men can be involved in the HIV/AIDS mitigation.

As a result of the observed gender role in HIV transmission, interventions have focussed on approaches aimed at empowering women (UNAIDS 2001a), an approach which fails to recognise the contribution of engaging men towards HIV/AIDS mitigation. The last decade has seen an explosion of HIV/AIDS interventions which focus on gender and women empowerment. The empowerment approaches however, have had limited effect on HIV/AIDS spread (Mane and Aggleton 2001). The optimism which rose about the success in HIV/AIDS intervention before 2000 (Parker 2002) seems to be lost.

HIV continues to spread and AIDS continues tonegatively affect the world. Uganda which experienced a decline in HIV/AIDS prevalence to less than $5 \%$ before and in 2001 has since seen a rise in HIV/AIDS prevalence of between 7 - 8\% (Republic of Uganda 2013). In Rwanda, while the decline has been observed, the prevalence has stabilised at about $3 \%$ since 2005 , with no further decline. The prevalence for women is $3.7 \%$ compared to $2.2 \%$ for men (Rwanda Biomedical Centre 2014). The thesis of this paper is that HIV/AIDS interventions recognise the influence of gender on the spread of HIV/AIDS and have thus focused on empowerment of women yet HIVAIDS spread and impact remains high. 
It is thus hypothesised that successful interventions will be those that will recognise that men can positively contribute to fighting against the deadly disease. We argue that as long as men are not positively perceived for their social position fully recognised in HIV/AIDS fight, the success of these interventions will not be realised. The paper presents that while the power relations between men and women over resource ownership and control continue to be central in the fight against HIV/AIDS, the fight cannot be successful unless program orientation targets men as well as women. This paper does not argue that men are/have not been involved in the fight against HIV/AIDS; rather it argues that the involvement of men has been conceived with a bias towards women. In addition, involving men is recent and limited in scope.

It is no wonder that since gender issues gained ground in HIV/AIDS interventions more than ten years ago, UNAIDS (2008) points out that gender inequality and the lack of empowerment of women and girls is one of the risk factors for transmission that has not been adequately addressed. We argue that the inadequacy does not lie in lack of empowerment and gender inequality; rather it lies within the failure to create balanced gender approach. We show that focussing on women as a vulnerable group not only reinforces gender inequalities which serve to disadvantage women and girls, but also curtails men's involvement into fighting the disease.

This is neither to be negative on the approaches to fight HIV/AIDS that have focussed on women as a distinct social group nor to disregard gender's role in facilitating HIV/AIDS spread and mitigation challenges, rather it is a proposition for an integration approach; one that considers the complementary work of both men and boys, and women and girls. In this paper, it is argued that the traditional practices and HIV/AIDS mitigation approaches should integrate men and respect what contribution men and boys make towards its mitigation. In the paper, we propose for a repositioning of men in the discourses, discussions and practices regarding HIV/AIDS mitigation.

\section{Methodology}

The methodology for this paper is extensive literature review. Existing scholarly literature and documentary reviews are important sources of information and data for any study. According to Skocpol (1984: 382),"if excellent studies by specialists are already available in some profusion, secondary sources are appropriate as the basic source of evidence for a given study". The review of the literature was made following thematic and content analysis approaches. Literature was first arranged according to themes and objectives as set by the paper. Following thematic arrangements, documents, books journal articles, were then analyzed for content and how it resonates with themes of focus.The examined literatures have discussions about gender and HIV/AIDS spread as well as mitigation of it. Further, the authors exploit different methodologies in 
their research and therefore critical review of these researches provides a good triangulation of data and information.

Theliterature reviewed had a focus not only on HIV/AIDS but also on gender and HIV/AIDS and men's involvement in HIV/AIDS spread. For example, Barnett and Whiteside (2002), O'manique (2004), Muriisa $(2009,2010)$ have looked at gender and HIV/AIDS in Africa. Country specific documents such as UNAIDS HIV/AIDS progress reports for Rwanda and Uganda were particularly invariable. In addition, new and emerging literature such as data on male circumcision and discordance has been reviewed and analysed with a purpose of finding out how men have been considered in the emerging interventions.

Critical review of such literature and other studies in the area of HIV/AIDS and gender and power relations provides a rich base for discussions pertaining to HIV/AIDS mitigation. O'manique (2004)for example, provides rich data on how gender in Uganda facilitates HIV/AIDS transmission and mitigation challenges, Ruxton (2004) provides rich information on how dealing with negative perceptions about male involvement may be overcome.

\section{HIV/AIDS in East and Southern Africa}

The first cases of HIV were identified in 1981 in the United States of America followed by new discoveries of two cases in Uganda in 1982 on the shores of Lake Victoria in a small fishing village Kasensero. There was no immediate linkage between the disease found in the USA and Uganda except for similar features of high fever, diarrhea and emaciation. Research into the disease in Uganda found more 17 cases in 1983 and the disease was found to be more prevalent among the highrisk groups such as sex workers (Okware, Opio, Musinguzi and Waibale 2001).Further studies and myths indicate that Uganda's HIV position by then is linked to the migration process within countries around including Rwanda and Tanzania (Barnnet and Whiteside 2002).By 2010 about 33.3 million people were living with HIV/AIDS majority of whom lived in sub-Saharan Africa, with 5.9 million living in South Africa (UNAIDS 2010), with other countries in the region having HIV prevalence exceeded 15\%(UNAIDS/WHO 2007, cited in Gebremedhin 2011).

East Africa exhibits a stable and controlled HIV prevalence; Tanzania registered about $3.4 \%$ between 2004 and 2008, Kenya, which registered about $16 \%$ (the highest percentage in the region in 2002, had by 2006 seen the prevalence reduced to about 5\%. Uganda, which had HIV incidence averaging about $18 \%$ in $1990 \mathrm{~s}$, was stabilized to about $7 \%$ between to 2005. Rwanda's HIV prevalence has been about 3\% since 2005 but is higher among women (3.7\%) than among men $(2.3 \%)$ (UNAIDS 2013, Rwanda Biomedical Centre 2014) ${ }^{9}$. New infections

${ }^{9}$ http://www.rbc.gov.rw/IMG/pdf/gender_assessment_report_b5_fin.pdf $02 / 01 / 2015$ 
however continue to be registered in the region. In Uganda, it is estimated that in 2007 there was 132,500 new infections (Uganda National AIDS Commission and UNAIDS 2009).

The number of women living with HIV/AIDS remains higher than that of men largely due to the vulnerability and risk of exposure by women compared to men (Higgins, Hoffman and 2010). Women account for more than half of the population living with HIV/AIDS in the world and this is even higher in Sub-Saharan Africa where the percentage is about 57\% (UNESCO 2005, UNAIDS 2010); and in Rwanda they account for $3.7 \%$ compared to $2.3 \%$ men (USAID 2013). There have been a number of initiatives to empower women but these initiatives have not been successful.

In the next section of the paper we discuss the theory behind "womenonly" approach and why it has failed and propose a need for a paradigm shift; a paradigm that sees men not as victimizers but also as victims within the framework of HIV and masculinities. Rwanda and Uganda are considered most successful countries in implementing gender specific programs to mitigate HIV/AIDS. Rwanda for example is the first country to establish Routine Couple Voluntary Counseling and Testing (CVTC) in antenatal care (Allen et al. 2014). Rwanda developed an accelerated plan (2010 -2014) for women, girls, gender equality in fighting HIV/AIDS (UNAIDS 2014)

\section{Theoretical Reflections: Women's Vulnerability to HIV/AIDS,Myth or Reality?}

How does HIV/AIDS relate with gender and how has HIV/AIDS spread been explained in the gender discourses? In understanding the relationship between gender and HIV/AIDS spread and gender and HIV/AIDS mitigation, we explore two dominant theories; the vulnerability and risk, and masculinity theories. Gender is conceived as "the relations of power between sexes, learned behaviours, the suppressed or accentuated physical and emotional characteristics and the forms of behavior that are desired or deemed inconsistent with masculinity or femininity" (Kaufman 2003, 4). Gender defines the differences between women and men in terms of what they know, what they believe, how they feel and behave. Gender has a strong influence on the spread, control and mitigation of HIV/AIDS.

Gender determines men and women responses to HIV/AIDS, the care and support differences and it also influences how women and men seek out and understand information about reproduction, sexuality and HIV risk, the sexual behaviours and practices that foster HIV risk (UNAIDS 1999). Gender relations and HIV are key drivers to HIV transmission especially in the sub-Saharan region. The relations of power determine resource control in the community and households, ultimately determining who makes decision and this has strong influence on HIV transmission. 
The vulnerability and risk, and masculinity theories are unidirectional and consider women to be vulnerable to HIV infection because of their position in society and therefore HIV/AIDS responses also target women. We argue that there is gross misrepresentation of men in this discourse and this may contribute to undermining the success of gender tailored HIV/AIDS interventions. In the African setting there is gender imbalance, which is rooted in property relations, as well as social cultures that recognise male dominance in decision-making and resource control. In this setting women are vulnerable to HIV infection. The vulnerability theory propounds that women are disadvantaged in their interpersonal relations with men due to limited resource control. The argument is that the socially disadvantaged woman is infected not because of her behaviour but because of the behaviour of the man. The social structures leave little room for women to negotiate for safe sex even when they are aware that their partners are infected with HIV because they depend on men for survival.

In many countries such as Mexico (Salgado, Diaz, and Maldonado1996), in Uganda (Muriisa 2010), in the United States of America (Wilton and Aggleton 1991),women face a challenge of sexual violence when they demand protected sex, because they have little say on such matters due to their dependence on men, and due to culture and social norms. Women's dependence on men is also reflected in migrant situations where studies show that the immediate problem for people who stay behind such as women and children is to survive socially and economically until the migrant returns or starts to send remittances home.

According to Bukenya (2010), in areas where the culture of extended family is still valued, the abandonment and loss of the bread winner increases the risk of HIV infection as women and children have to make desperate choices to cope. Once there is an interruption in the income flow and the absence of the husband, women resort to pursuing a variety of coping strategies including additional sexual partners resulting into HIV infection. In the study of migrant and non-migrant couples in rural South Africa, the woman was the infected partner in nearly one-third of the discordant couples (Lurie et al 2003); this can be attributed to culture that makes women dependant on men for their survival.

According to the vulnerability theory therefore, women's increased HIV infection becomes a reflection of gender inequality which is grounded in the social cultures and institutions which gives men the power to control and use resources to the disadvantage of women. Women's vulnerability therefore, is largely due to the social institutions which deny them the right to own property and subjugate them to the care of, the home, children and men. The very existence of women therefore depends on men's ability to provide, and women's decision-making even in matters of sex is very much limited. Ultimately, women do not have the right to determine when to have sex and what type of sex to have, and to negotiate for safer sex. 
Women's vulnerability and risk translates into more women-focussed programs, programs that obscure the involvement of men in fighting for equality and disease control. In the struggle against HIV/AIDS women continue receiving attention as vulnerable, victims, ones who bear the burden of care giving and support, bearer of children and all other HIV/AIDS related burdens. Men are depicted as victimisers and "carriers of diseases" from their long migration journeys in such of livelihoods for the family (Barnett and Whiteside 2002). As such, mitigation efforts have concentrated on the women ignoring the social, economic, and cultural realities on ground which facilitate HIV/AIDS transmission.

Within the struggle for gender equality, women feel strongly that working with men dilutes their struggle. Men are depicted as always striving to remain above women and unwilling to change. The women who feel this way are opposed to anything regarding male involvement. In the women movement for gender equality, there are many women who feel that men's involvement in the struggle dilutes it. They hold the view that because men and boys are the beneficiaries of privileges and discrimination against women and girls, they cannot understand women's struggle (Njoki 2005). Many doubt that men and boys can be fully committed to a change that would make them lose a lot of privileges such as unprotected sex which they enjoy.

There is evidence however, showing that men are willing to change and are committed to work towards changing their gender attitudes and behaviours (Peacock. et al 2008) and there are men who do not conform to the dominant masculinities. Thus, Cornwall $(2000,23)$ argues that "while it is unquestionably the case that many men do occupy positions of power, it is one thing to name those subject positions and another to go on to presume that all men have access to these positions or indeed want to take them up". Not all men are privileged to have the dominant positions, there are many situations where men suffer in the same way as women and sometimes men may feel powerless at the hands of women or men; men are also vulnerable in other more subtle ways (Esplen 2006).

In the case of HIV infection, studies show that men are equally vulnerable and get exposed to HIV like women do. Men are constrained by culture which imposes on them the need to have multiple partners, to bear children and particularly if the children of their partners are girls. The demand for the man to produce boys to keep the linage exposes them to HIV/AIDS. Any man who changes or deviates from such behaviors therefore, is met with resistance and isolation by his peers and if a supportive environment is not provided, they fall back.

Therefore, some men like the women may not resist the cultural demands. Men are infected as a result of their seemingly accepted lifestyles in countries where masculinity dominates and women are infected by the same men who ride on masculine cultural norms. In 
essence, both women and men get infected with HIV. Indeed as Baylies $(2004,72)$ argues, 'culturally created norms of masculinity place men at high risk of becoming infected through accepted male lifestyles. Culturally created norms of femininity place women and children at high risk of becoming infected through the same male lifestyles".

It is important to note that men who are under intense pressure to see things change would support women in the struggle for equality and against HIV/AIDS as opposed to the vulnerability and risk theory that consider men to be resistant to change. Not all men therefore, are opposed to change. Sanday Ruxton thus notes that, "in all parts of the world, there are men who are aware of the straightjacket imposed upon them by traditional notions of masculinity, and who are more open to reassessing their roles and responsibilities (Ruxton 2004, vii). UNAIDS $(2001,9)$ points out that men's actions just like those of women, are constrained by traditional and widely held beliefs and expectations about appropriate and inappropriate forms of behaviour. In the effort to fight HIV/AIDS over generalizing and putting men in one bracket as if they all engage in gender-based violence, rape and promiscuous activities leave men who would positively contribute alienated. Thus it is argued that, "language that leaves males feeling blamed for things they haven't done, or for things they were taught to do, or guilty for the sins of other men, will simply alienate most boys and men"(Kaufman 2004, 25).

Are women more vulnerable than men? In the framework of vulnerability as earlier discussed, women are considered more vulnerable, and men dominant. Critical examination of this view however finds that in the gender discourses an aspect of men as a vulnerable social group is grossly under looked and women's position overstated. Men are disadvantaged due to social institutions and culture which they have to uphold, and the social demands to conform to the dominant stereo types. The stereotypes constrain men not only from participating in HIV/AIDS activities but also from seeking HIV related assistance and revealing a HIV-positive diagnosis because they fear loss of respect and feelings of guilt towards their partners and children. Baker and Ricardo (2005) report that throughout Sub-Saharan Africa, only a small number of young men seek HIV testing and that women are more likely than men to seek testing and to disclose their HIV status. They related this observation with common perception among men that clinics are "female" spaces and that "real men" do not get sick. Getting involved in HIV/AIDS care and prevention related activities may put men in the same situation of feeling unmanly and the fear of rejection by their peers.

In terms of mitigation, we need to understand different masculinities facilitate HIV spread and constrain HIV mitigation. Connell's theory of masculinity helps us to understand that there are different masculinities; hegemonic, subordinate and marginal (Connell 1995). This theory helps us to understand that gender and social construct allows room for change 
in behaviour, practices and attitudes. In other words behaviours learnt can also be unlearnt through new forms of socialisation. Cornwall (2000) shows that not all men conform to the hegemonic version of masculinities and that those who do not conform find themselves disadvantaged and even discriminated against. Thus, "men's actions like those of women are constrained by traditional and widely held beliefs and expectations about appropriate and inappropriate forms of behaviour" (UNAIDS 2001). By showing that some men do not actually match up to idealised forms of masculinities, spaces can be opened up for a reflection on how men can be involved in developmental activities and fighting HIV/AIDS in particular.

Recognising that men can also feel powerless in some situations and that they can also reflect on their behaviours and positively respond to fighting HIV/AIDS, is the rightful path towards achieving a successful fight against HIV/AIDS. Interventions involving men in the advocacy for moving out of the confines of culture and the appeal to gender divisions at home, work and other daily practices will have greater impact. Men should be viewed as change agents who can contribute positively to the fight against HIV/AIDS. Seeing men as allies and not as enemies may therefore be a solution to a long standing problem of successful HIV intervention.

Most interventions are less successful because they do not take into account the identity constructions of men. The influence of cultural norms regarding manhood, the traditional beliefs of inheriting widows, sharing wives and polygamy, all have gender implications for HIV transmission, since they shape the behaviour of men. Seen from these lens therefore, men should not be considered as a problem, rather they should be considered as gendered beings as well. The social construction of the man is so powerful and therefore should be targeted for successful intervention into HIV/AIDS. Cleaver (2002) argues that gender relations are key issues in all efforts to reduce gender inequalities and vulnerabilities and that men should be seen not as some kind of problem, but rather as part of the solution, as allies and partners in the fight against HIV/AIDS.

\section{Rethinking Men and HIV/AIDS Mitigation: Theory and Practice}

The discussion in the above section shows that the vulnerability and risk of women as well as masculinity are largely the reason why HIV/AIDS in Africa has continued to spread. We have argued that the discussions and debates surrounding HIV/AIDS transmission, impact and mitigation, have largely engendered men. Existing studies confirm this assertion. Studies show that men have not been the main targets of health interventions including HIV because of the consideration of the vulnerabilities of women to HIV infection. Center for the study of Adolescence (2008) in the study of Uganda and Lesotho finds out that men were hardly the main target of most sexual reproductive health programs and therefore there are few programs which recognize the 
important role that men play. In addressing HIV/AIDS Njoki (2005) points out that working with men and boys are a new approach and experience with it are recent, sketchy and much less tested.

In fighting HIV/AIDS, literature shows that the fight is marred by men's possession of resources, authority and power which they use to their advantage and to the disadvantage of women. The approaches to fight HIV/AIDS which have targeted women therefore often fail. The inherent weakness of 'women only' approaches has become most devastatingly apparent in the light of HIV/AIDS epidemic. Programs that focus on empowering women to negotiate safer sex have minimal impact in societies where it is men who decide when and with whom to have sex, and when and if to use condoms (Esplen,2006). Seckinelgin (2002) argues that men have been largely ignored by the preventive approaches such as a focus on women attending antenatal clinics, prevention of Mother-to-Child transmission, compulsory testing during pregnancy which, more often than not, does not include the fathers. Such an approach leaves the women helpless in the effort to mitigate HIV/AIDS. We argue that women's vulnerability approach largely undermines the effort to fight HIV/AIDS in that men themselves are also vulnerable. We argue that men possess a different vulnerability however, a vulnerability that is highly entrenched in the cultures of these communities, where male superiority complex creates a situation of selfexclusion. This, thus, calls for male-specific targeting services or services that target both female and male not as independent but dependent on each other for HIV/AIDS successful interventions.

As earlier discussed, in the fight against HIV/AIDS, men are presented negatively as "irresponsible, aggressive and difficult to work with" (UNAIDS 2001, 9). Men have been largely and generally presumed to be powerful obstacles to the containment of the spread of HIV/AIDS. In most literature, African men are often portrayed as powerful, promiscuous, and resistant to change. It is presumed that efforts to change men's behaviour are met with resistance. Thus, Higgins, Hoffman and Dworkin (2010) point out that "unlike women's, men's gender socialisation is either ignored or perceived as immune to change. For example, it is presumed that men resist using condoms even when they are aware that they are protective; they do not negotiate for sex or even safer sex; they force women to have sex and refuse to use condoms. There is therefore a presumption that women want to use condoms and men do not want even when they know that there is HIV infection.

The perception that men refuse to use condoms is a one sided argument since there are no studies that have looked at women's use and response to condom use in Uganda and Rwanda. There are studies which have been done in United Kingdom and United States of America which show that actually women resist use of male condoms citing loss of pleasure resulting from use of condoms(Higgins and Hirsch 2008). Such studies have not been emulated in Uganda and Rwanda for one to generalize. 
Moreover, the acceptability of female condom in 1998 was low in Uganda. A study on the acceptance of new female condoms in Uganda (Wanyenze, et al 2011) shows that acceptance was high, but this was only a pilot that was done on a very low scale. In Rwanda, specific target groups identified the use of female condoms as an empowerment tool for women although uptake was also on a low scale (Ministry of Health, Republic of Rwanda and Rwanda Biomedical Center, 2014).

Studies have also shown that women also engage in concurrent relationships and are almost as likely to bring HIV into the relationship as are men (Higgins, Hoffman and Dworkin 2010). In Burkina Faso, Cameroon, Ghana, Kenya and Tanzania $30 \%$ to $40 \%$ of HIV infected couples, women were found to be HIV positive and the man HIV negative(de walque Damien 2006). In Uganda, Rakai district, in a large portion of sero-discordant couples, the woman was HIV positive (Serwadda et al 1995). These studies dispel the common perception that unfaithful males are the link to HIV transmission. The vulnerability of women to HIV infection does not only appear in HIV spread but also in the fight against HIV/AIDS.

Men's involvement is still limited in scope covering only issues related to distribution of condoms. The encouragement of men to circumcise might be a move into the right direction, but it seems to carry the same "voice" that men are responsible for spreading the disease. These efforts may be undermined by the same sentiments that men are the perpetrators, and spreaders of the disease (Marks 2002). Moreover circumcision was perceived as only aiming at protecting men and not women. Junga and Oinas (2004) argue that male circumcision is based on the fact that subSaharan transmission is predominantly heterosexual and primarily from male to female, and therefore circumcision is focused solely on protecting the male from becoming infected with HIV.

We argue that men's contribution should be given more value than being included in the fight against HIV/AIDS on the basis of their seemingly oppressive and dominant position in the spread of HIV. The value of men in fighting HIV/AIDS is heavily underlooked. Most of the interventions target violence and sexual coercion than any other gender strategy. A compendium of HIV/AIDS gender programs in Africa (USAID 2009) found that 30/31 programs examined sexual violence and sexual coercion. The report also indicates that men were reluctant to participate in these programs because they were negatively perceived. This confirms the argument that programs that negatively represent men are shunned by men and may not be successful.

Further, it is often construed that men are and have the knowledge about HIV/AIDS as compared to women. Studies however show that women as well as men lack the necessary information regarding sexuality. In the first instance, matters of sex are often not discussed especially with adolescents. Boys and girls do not receive the right information at an early age to be able to prepare for HIV prevention. Thus it is noted that 
even when sexuality for women in African societies is ignored, they often receive some information and education to prepare them for reproductive role. For men however, there is a complete absence of reliable information on sex (UNAIDS 1999). With this lack of knowledge about HIV/AIDS, men's not women's vulnerability to HIV/AIDS becomes eminent.

For this reason, there is a need to give attention to both men and women similar attention when fighting against HIV/AIDS. Increasing men's involvement does not come easy considering that culture takes time to change, but with a change of strategy and approach, it may be possible. USAID (2009) points out that several programs need to create a more supportive social environment so that men are encouraged when they deviate from traditional behaviour thus making behavioral change easier. As noted earlier, men are under pressure to conform to certain beliefs, practices and norms of behavior. In the next section, we examine programs which have involved men in fighting HIV/AIDS and their successes.

\subsection{Involving Men in Fighting HIV/AIDS}

Since the first world conference on women in Mexico city in 1975 and following reviews (Nairobi and Beijing conferences) it continues to be agreed that while progress is being made in the promotion of equality in politics, economics, there are still major obstacles to achieve gender equality and more so in health where the situation of the majority of women is getting worse day by day (Njoki 2005). In 2009, twenty four years after the Nairobi conference of 1985, fourteen years after the Beijing conference of 1995, the condition of women did not improve significantly. Instead new forms of gender violence are on the rise, while HIV/AIDS pandemic continues to impact negatively on the positive gains of gender equality (Ndulo and Grieco 2009, 2).

In Rwanda despite the gender specific programs addressing gender-based violence, the vice seems an accepted norm by the local population especially the young women. Data from the 2010 DHS survey indicates that there is a popular belief that a husband has a right to beat his wife if she refuses to have sexual intercourse with him. Young women present a higher rate of acceptance than older women; 40\% (30-34 years) compared to $37 \%$ ( $45-49$ years) agreeing, that a husband has the right to beat his wife if she refuses to have sex with him (UNESCO, 2013).

Increasingly it is being recognized that lack of men's involvement in gender equality activities may be one among many explanations as to why the situation of women is not getting any better despite the empowerment and equality programs. "As key decision-makers, men and boys are essential partners in addressing today's public health challenges and in building more equitable and prosperous societies" (Center for the study of Adolescence, 2008). Kaufman (2003) points out that men are the gatekeepers of current gender orders and are potential 
resistors of change, and therefore, failure to effectively reach men and boys makes many of the efforts to promote gender equality simply ignored or thwarted.

While, involving men in fighting HIV is recognized, this has met a lot of resistance and negative considerations. Men tend to be misrepresented as being irresponsible, aggressive and difficult to work with (UNAIDS 2001). Involving boys and men in the fight against HIV/AIDS as earlier indicated, is likely to be more successful than a focus on women alone. It has to be noted that the dominant theory in the gender-HIV/AIDs discourse-"vulnerability and risk" has proved to negatively impact on the success of programs. As earlier discussed most literature depict women as vulnerable and at risk of infection of HIV/AIDS as a result of men's sexual activity and practices (see for example, Omanique 2006, Barnett and Whiteside 2006). This has had limited success due to failure by men to support and uptake HIV/AIDS programs.

Involving men in the fight of HIV/AIDS can lead to overcome the challenges which facilitate HIV/AIDS transmission and impacts. It is widely agreed and acknowledged that men control, power authority and economic resources on which the HIV/AIDS fight depend. Without adequate involvement of men in the fight therefore, it is unlikely that resources available will be enough. Men must be in the forefront of prevention of HIV infection and mitigation of the impact of the epidemic on the individuals and communities, and provision of health care and compassion, just like they have taken leadership in other sectors. Kaufman $(2004,21)$ proposes that increasing gender equality should include but not limited to: create large scale and broad social consensus on a range of issues that have been previously marginalised as issues of importance to only women when in fact they are also issues for men; develop effective partnership between men and women, and institutions representing the interests of men and boys and those representing interests of girls and women; contribute to raising the next generation of boys and girls committed to promoting gender equality and human rights of both women and men.

In the context of HIV/AIDS, the first proposition could be viewed in creating consensus that HIV/AIDS affects men and women in similar ways, they both die by it and suffer the same way. Therefore, there is a need to build consensus that both groups are committed to fighting HIV/AIDS. As it is presented in most literature, men are perceived as resistant to change and lack commitment to fighting HIV/AIDS. It should be noted however, that fighting HIV/AIDS is both a commitment by men and women and therefore means of getting them both to fight HIV/AIDS should be sought.

The second proposition calls for working together as individuals and as groups instead of working in isolation. The third proposition is about starting early and target the young generation. This stems from the view that culture is not easily changed, it takes time to build and therefore it 
may take the same time to change. Interventions which focus on young men and boys as they begin to have intimate sexual relationships are likely to have wider impact than those that target men and women as adults. Culture (values) take time to build, and therefore cannot be easily changed (Hofstede and Hofstede 2005). In the sections that follow, we discuss ways men can be involved in fighting the spread and mitigation of HIV/AIDS challenges.

\subsection{Building Men's Groups}

As indicated above, involving men in the fight against HIV/AIDS is the strategy that may lead to success. It is also indicated that since men control a lot of resources, economic, political and social resources such as taking decisions in the family, they may not be willing to give up these powers in the interest of equality. But, men must be engaged as they will have to give up something for the struggle to be won. Definitely, this is not an easy task, but one that may be pursued with successful results. The starting point should be the socialisation process. Men should be allowed to be part of the talking against the spread of HIV/AIDS. Women all over the world have formed themselves into groups to discuss HIV/AIDS.

Through the women groups, sharing of HIV/AIDS spread, control and mitigation is has been made possible. According to Muriisa (2010) groups facilitate sharing of experiences and dealing with stigma. Groups facilitate information sharing, access to social and psychological support. In addition, people who join groups especially those dealing with HIV/AIDS are more tolerant and accommodate differences (Muriisa and Ishtiaq 2011). It therefore goes without saying, that creating forums for men to share and discuss and agree on actions to deal with HIV/AIDS may help men in overcoming stigma, certain masculinities and to mobilise other support. Groups work to raise awareness, promote selfreflection and in some cases may promote social action (Kaufman 2003).

In a Brazilian study (Pulerwitz, et al. 2010), it was found that young men who participated in the groups appreciated and changed their attitudes towards women/girls because of the exposure to information and the discussions with peers also increased change in attitude to self-reflection and role plays. Muriisa and Ishtiaq (2011) found a positive relationship between joining groups and the HIV/AIDS program successes in dealing with stigma, social isolation and information dissemination. In Rwanda, RWAMREC a local, grass-roots organization of Rwandan men engaging men in gender issues is promoting 'positive masculinity' with a key focus on promoting gender equality and women's empowerment. The organisation has promoted men's engagement in activities mitigating HIV/AIDS. Discussions held among men within RWAMREC help to 
change their attitudes towards property ownership. The popular belief that property ownership was men's monopoly is dispelled ${ }^{10}$.

\subsection{Reach Out to Men Directly}

Another way to get men involved in HIV/AIDS activities is to reach out to them directly. Most efforts to involve men in reproductive health education such as prevention of mother to child transmission of HIV have failed (Pulerwitz, et al. 2010). Efforts to involve men often begin by sending messages to men through their wives attending antenatal and postnatal clinics. However, very few men turn up on the next antenatal day. Sending these messages through community outreach programs is more promising. Rwanda adopted the strategy of partner counselling and HIV/AIDS testing, an initiative to encourage male partners of pregnant women to test and get counselled with their partners. This strategy saw an increase in men being counselled and tested for HIV/AIDS.

According to Republic of Rwanda Ministry of Health and Rwanda Biomedical Center (2014), this was an outcome of activities implemented at the community level. Results available show that the total number of couples tested for HIV has increased tremendously since the introduction of couple counselling strategy. $16 \%$ male partners of pregnant women were counselled and tested between July 2002and June 2003 and this increased five times to 85\% in 2013 (Allen et al 2014, Republic of Rwanda Ministry of Health and Rwanda Biomedical centre 2004, 33).In Uganda a combined multichannel mobilization strategies including; local forum theatre, community dialogues, family support groups for pear support and follow-up, led to the improvement of male involvement in PMTCT in Eastern Uganda (Buyinza and Nakandha 2014). According to these authors, the proportion of pregnant women tested with partners was $16 \%$ in 2003 and this increased to $84 \%$ between 2009 and 2012. During the period 2009 and 2012, the prevalence for HIV was $3.1 \%$ for men and $2.7 \%$ for women in the eastern part of Uganda. Overall however, the national referral hospital results indicated that male partner testing remains low among expectant mothers (Nabweteme et al 2014).

\subsection{Men, HIV/AIDS Care and Support}

Involving men in the care and support of those living with HIV/AIDS is the way change can be effected in the care and support system. Men control resources, finances and the economic, political and social system on which the efforts to mitigate HIV/AIDS depend. Without adequate involvement of men, it is unlikely that the resources available will be enough. Men must be involved in the prevention of HIV infection, mitigation of the impact of the epidemic and care and support just like they have taken the lead in other sectors. Apart from the provision of

\footnotetext{
${ }^{10}$ http://www.unwomen.org/en/news/stories/2013/11/in-rwanda-men-work-tochange-attitudes-and-confront-violence, Accessed on 06/04/2015
} 
resources, letting men take care of the sick is a way to get men realise the challenges of care and support. In Rwanda, RWAMREC trainings incorporates role-play, such as men carrying a toy child on their back while having to cook, clean and farm. The role plays are to demonstrate the difficult task of social responsibilities, tasks often left for women to carry ${ }^{11}$. The aim of these training is to change social attitudes towards men's vs. women's roles.

Other studies show that working directly with men are more promising in creating gender awareness and reducing violence against women. Working with men directly helps men to reflect on the practice of masculinities, reshape men's understanding of their own and others' HIV/AIDS vulnerabilities and risks, and encourage them to change their sexual behaviour (Peacock and Levack 2001)

\subsection{Men and Spaces of HIV/AIDS Discussions}

Involving men should also consider spaces where gender issues are often discussed so that such issues are explored exhaustively. In fighting HIV/AIDS, projects have focused on bringing men and women together or women and men as individual groups through workshops to discuss gender issues as they affect HIV/AIDS interventions. But, findings indicate that gender workshops often tend to avoid issues of power relations in order to maintain harmony and cohesion among groups (Keating 2004). That many facilitators tend to steer debate away from a deeper debate about the rules that promote women exclusion thinking that strong divisions between men and women will ensure and disrupt continuous discussions over these issues and eventual failure to reach a consensus.

For example, it is often perceived that men may not easily discuss and accept to change their behaviour and gender roles and gendered power relations. However, the study by Keating found that men were seemingly interested as women in discussing changes in gender and power relations (Keating 2004). Therefore, by considering how gender issues should be introduced, how discussions should be guided and exploring the situations of men and the cultural and social values that influence their behaviors, men can be easily involved into HIV/AIDS activities in a manner that is more positive on the roles they can play in fighting HIV/AIDS. The positive way to introduce such discussions is to allow men to present how they are constrained by social and cultural values to behave the way they do. Keating indicates that introducing conversations in this way may give people a chance of learning from each other's experiences and aspirations. Kaufman (2004) proposes that negative language that would present men as inhuman, violent and resistant to change should be avoided. In both Uganda and Rwanda, men have been engaged through community HIV/AIDS prevention programs.

${ }^{11}$ See footnote 5 above 
As mentioned earlier, in Rwanda, civil society organisations such as (Rwandan Men's Resource Centre (RWAMREC) provide space for discussion on GBV and are rolling out programs for sensitization and awareness campaigns on the role men have to play in promoting gender equality, reducing GBV and HIV at grassroots levels. Community trainings on behavior and mindset change for greater gender equality, through positive masculinity and male engagement are being implemented $^{12}$. In Uganda, engaging men has been up scaled at community level through community male leaders who encourage men to engage in the fight against HIV/AIDS ${ }^{13}$.

\section{Conclusion}

Power, gender and HIV spread and AIDS impacts in East and Southern Africa are closely linked. This paper has been an attempt to redirect the discussions and debates about HIV/AIDS mitigation with respect to gender, with particular emphasis on repositioning men in the HIV/AIDSgender discourses. What we have shown in this paper is that current gender approaches to HIV/AIDS alienates men in so many ways including negatively representing them. While gender should be understood to be all inclusive of men and women and consider the social constructions of the "man and the woman", current approaches have focussed on the sexual differences equating women as gender, consequently men have been engendered in the gender-HIV/AIDS discourses, and this has negatively affected the HIV/AIDS mitigation efforts.

This paper does not deny the fact that the current gender approaches help in exposing the gender aspects that facilitate HIV/AIDS transmission and a challenge to its mitigation.It brings out to light the key drivers of HIV spread and key challenges to its mitigation. It therefore tells us how best HIV prevention and mitigation can be achieved. As the paper shows, there is no denial that HIV especially in Southern and Eastern Africa and particularly in Uganda and Rwanda rides on the power and gender relations. But the weaknesses in the gender approaches overshadow the benefits of an all-inclusive gender approach. Giving examples from Rwanda and Uganda where there has been marked success in the fight against HIV/AIDS men's role in HIV/AIDS mitigation should be approached differently from the earlier approaches which have tended to exclude them.

We conclude that there is a need to reposition men and consider them not only as gendered beings but also ones who can positively contribute to successful HIV/AIDS intervention. Of course this is not to exonerate

\footnotetext{
${ }^{12}$ http://www.rwamrec.or/spip.php?article105 31/01/2015.

${ }^{13}$ www.pedaids.org/blog/entry/promoting-male-involvement-inuganda, 31/01/2015
} 
those men who are strongly influenced by hegemonic masculinityand thus are violent towards women and who do not find positive value in everything women do, or the good approaches that consider women as gendered beings. We thus conclude that policies that focus on gender, power and HIV/AIDS have strong influence on mitigation but these policies need to consider the positive contributions of men as well as their negative contributions to addressing the HIV/AIDS challenges.

The paper observes that men's sexuality and behaviour are affected by the cultural and social aspects almost in the same way as women. Men are constrained to behave as "real men" while women are constrained to behave as "real women" and be submissive to male dominance. The example we provided regarding accepted norm of GBV in Rwanda is an attestation to this claim. The consequence of this is that HIV transmission and spread thrives. Policy makers should view HIV spread, partly, as a consequence of this situation rather than focusing on women's vulnerable position alone.

\section{References}

1. Allen Susan, Karita Etienne, Nsanzimana Sabin, Ndagije Feix, Wall Kristin, Mukanyango Heamine, and Mugwaneza Placidie (2014), "Evolution of Couples Voluntary Counseling and Testing for HIV in Rwanda", Paper presented at $20^{\text {th }}$ International AIDS Conference AIDS 2014, Melbourne Australia, http://pa.aids2014.org/session.aspx?s=1087\#4

2. Baker Gary and RicardoChristine. 2005. "Young men and Construction of Masculinity in Sub-Saharan Africa, implications for HIV/AIDS conflict and Violence." in Social development Paper No.26: World bank.

3. Barnett Tony and Alan Whiteside. 2002. AIDS in the TwentyFirst Century, Disease and Globalisation. New York: Palgrave Macmillan.

4. Baylies Carolyn. 2004. "Cultural Hazards Facing Young People in the Era of HIV/AIDS: Specificity and Change." in The Political Economy of AIDS in Africa, edited by N. Poku K and A. Whiteside. Burlington: Ashgate.

5. Bukenya Daraus. 2010. "Gender Perspectives on Preventing and Coping With HIV/AIDS in Post Conflict African Societies". Retrieved from http://www.certi.org/publications/AIDS_symp/Daraus_Bukenya. htm 22/03/11

6. Buyinza W. Keneth and Nakandha C. Kaamu (2014), A combined Multichannel Mobilization and Home-Based HCT Strategy Improves Male Involvement and Outcomes for PMTCT in Rural eastern Uganda, Paper presented at $20^{\text {th }}$ International AIDS Conference AIDS 2014, Melbourne Australia, http://pa.aids2014.org/session.aspx?s=1087\#4 
7. Center for the Study of Adolescence, 2008.Promoting the Involvement of Boys and Men in Reproductive Health and HIV/AIDS: Findings From the Review of IPPF Projects in Lesotho and Uganda, Nairobi, CSA .

8. Cleaver Frances. 2002 Men and Masculinities: New Directions in Gender and Development. In F. Cleaver, Masculinities matter! Men, Gender and Development, pp. 1-27, London: Zed Books.

9. Connell W. Raewyn.1995.Masculinities, Cambridge: Polity Press

10. Cornwall Andrea. 2000 "Missing men? Reflections on Men, Masculinities and Gender in GAD", IDSBulletin, Vol3, No.2: $18-27$.

11. Department of Health South Africa. 2003. Men in HIV/AIDS Partnership, Provincial Consultative Workshops May - July 2003, South Africa de Walque Damien. 2006. Discordant couples : HIV infection among couples in Burkina Faso, Cameroon, Ghana, Kenya, and Tanzania, World Bank, Working paper WPS3956,

12. Esplen Emily 2006. "Engaging Men in gender Equality: Positive Strategies and Approaches: Overview and Annotated Bibliography",http://www.bridge.ids.ac.uk/reports/BB15Masculi nities.pdf22/07/11

13. Gebremedhin Samson. 2011. "Male Circumcision and its association with HIV infection and Sexual transmitted diseases: Evidence from 18 demographic and Health Surveys in SubSaharan Africa, Sahara Journal (8) 1 April 2011.

14. Grant Miriam and Parpart Jane. 2010. "Gender and Home-Based Care for HIV/AIDS and TB Patients in Rural and Urban Zimbabwe, Canadian Journal of African Studies (CJAS) 44(3), $503-523$

15. Higgins A. Jenny and Hirsch S. Jenniffer. 2008. "Pleasure, Power, and Inequality: Incorporating Sexuality Into Research on Contraceptive Use",American Journal of Public Health, Vol. 1 98, No. 10 (1803-1813)

16. Higgins A. Jenny, Hoffman, Susie and Dworkin, L. Sari. 2010. 'Rethinking Gender, heterosexual men, and Women's Vulnerability to HIV/AIDS: Time to Shift the Paradigm, American Journal of Public Health, Vol. 100, No. 3 (435-445)

17. Hofstede Geert and Hofstede J. Gert. 2005. Cultures and Organisations Software of the Mind: Intercultural Cooperation and its Importance for Survival, New York, McGraw-Hill

18. Junga Katarina and Oinas Elna. 2004. 'Preventing HIV? Medical Discourses and Invisible Women' in Arnfred Signe. 2004. Rethinking Sexualities in Africa, Uppsala, Nordiska Africain Institutet

19. Kaufman Michael. 2003. "Addressing and Involving men and Boys to Promote Gender Equality and End Gender Discrimination and Violence "http://www.michaelkaufman.com 
/wp-content/uploads/2009/01/kaufman-the-aim-framework.pdf, $23 / 07 / 11$

20. —. 2004. "Transforming Our Interventions for Gender Equality by Addressing and Involving Men and Boys: A Framework for Analysis and Action" in Gender Equality and men: Learning from Practice, 2004, edited by S. Ruxton, GB, Oxfam

21. Keating Maree .2004. "The things They Don't Tell You About Working With Men in Gender Workshops" in Gender Equality and men: Learning from Practice, 2004,edited by S. Ruxton, S. GB, Oxfam

22. Lurie N. Mark, Williams G. Brian, Zuma Khangelani, MkayaMwamburi David, Garnett P. Geoff, Sweat D. Michael, Gittelsohn Joel, Salm S. Abdool Karim. 2003. "Who infects whom? HIV-1 concordance and discordance among migrant and non-migrant couples in South Africa" .AIDS, Vol. 17. No. 15; 2245-2252

23. Mane Purnimaand AggletonPeter.2001. "Gender and HIV/AIDS: What Do Men have to Do with it?" Current Sociology Vol. 49:23-37.

24. Marks Shular. 2002. "An Epidemic Waiting to Happen? The Spread of HIV/AIDS: South Africa in Social and Historical Perspective" African Studies, 61(1) 13 - 26

25. Muriisa Roberts. 2009.The AIDS Pandemic in Uganda: Social Capital and the Role of NGOs in Alleviating HIV/AIDS Challenges, Berlin, VDM Publishing House

26. - . 2010. The role of NGOs in Addressing Gender Inequality and HIV/AIDS in Uganda, Canadian Journal of African Studies (CJAS) Vol.44, No.3, 605 - 623

27. Muriisa Roberts and Ishtiaq Jamil. 2011. "Addressing HIV/AIDS Challenges in Uganda: Does Social Capital Generation by NGOs Matter?"Journal of Social Aspects of HIV/AIDS, 8 (1) 1 - 12

28. Nabweteme Mugerwa, Zamukwaya Z. Namala-Lugobi L., Ayanga Matovu, Kakande, Kamya et al (2014), Male partner HIV testing and Sero- Discordance Rates among Pregnant Women; Moving toward eMTCT and Reduction of New HIV infections, Mulago Hospital, Kampala, Uganda, Paper presented at $20^{\text {th }}$ International AIDS Conference AIDS 2014, Melbourne Australia, http://pa.aids2014.org/session.aspx?s=1087\#4

29. Ndulo Muna and Grieco Margaret. 2009. "Introduction, Power, Gender, and Social Change in Africa, in Power, Gender and Social Change in Africa, Edited by M. Ndulo and M. Grieco, Newcastle, Cambridge Scholars Publishing

30. NjokiWainaina. 2005. The Role of African Men in the Fight Against HIV/AIDS,http://www.ww05.org/english3/speech/5.3. NjokiWainana.pdf accessed on 29/07/11

31. Okware Sam, OpioAlex, MusinguziJoshua, and Waibale Paul. 2001. Fighting HIV/AIDS: Is Success Possible? Bulletin of the World Health Organisation 79:1113-1120. 
32. O'manique Colleen. 2004. Neoliberalism And AIDS Crisis in Sub-Saharan Africa: Globalisation's Pandemic. Basingstoke: Palgrave-MacMillan.

33. Parker Richard. 2002. The Global HIV/AIDS Pandemic, Structural Inequalities, and the Politics of International Health, in American Journal of Public Health, Vol. 92. No. 3173

34. Peacock Dean, Redpath Jean, Weston Mark, Evans Kieran, Daub Andrew and Greig Alan. 2008. Literature Review on Men, Gender, Health and HIV and AIDS in South Africa, Sonke Gender Justice Network, USAID.

35. Peacock Dean and Levack Andrew. 2001. The Men as partners Program in South Africa: Reaching men to end gender-based violence and Promote Sexual and reproductive Health. International Jounal of Men's Health, Vol. 3, 173 - 188

36. Pulerwitz Julie, Michaelis Annie,Verma Ravi, Ellen Weiss .2010. "Addressing Gender Dynamics and Engaging Men in HIV Programs: Lessons Learned from Horizons Research", Horizons Program, Public Health Reports March-April 2010, Vol. 125

37. Putzel James. 2004. The Politics of Action on AIDS: A Case Study of Uganda. Public Administration and Development (24):19-30.

38. Republic of Uganda, 2013. 2013 Uganda HIV and AIDS Country Progress Report, http://www.unaids.org/sites/default/files/country/documents/UG A_narrative_report_2014.pdf. accessed 06/04/2015

39. Rwanda Biomedical Center2014.Rwanda, Global AIDS Response Progress Report (GARPR) 2014,Kigali, Rwanda Biomedical Center and Ministry of Health

40. RuxtonSanday. 2004. "Introduction" in Gender Equality and men: Learning from Practice,2004,edited by Ruxton, S. GB, Oxfam

41. Salgado deSnyder ., Diaz, Perez, and Maldonado, M. (1996). AIDS: Risk Behaviours Among Rural Mexican Women Married to Migrant Workers in the United States. AIDS Education Preview, Vol.8, No.2, 134 - 142.

42. Seckinelgin Hakan. 2002. "Time to stop and think: HIV/AIDS, Global Civil Society, and People's Politics." in Global Civil Society 2002, edited by H. Anheier, M. Kaldor and M. Glasius. Oxford: Oxford University Press.

43. Serwadda D, Gray RH, Wawer MJ, Stallings RY, Sewankambo NK, Konde-Lule JK, Lainjo B, Kelly R. 1995. "The social dynamics of HIV transmission as reflected through discordant couples in rural Uganda" AIDS Vol. 9, No.7, 745 - 750.

44. Skocpol, Theda. 1984. Vision and Method in Historical Sociology. Cambridge Cambridgeshire ; New York: Cambridge University Press.

45. UNAIDS. 1999. Gender and HIV/AIDS: Taking Stock of Research Programmes, Geneva, UNAIDS 
46. - . 2001. "Men, Culture and HIV/AIDS." vol. 2008: http://www.thebody.com/content/art715.html accessed $120 / 03 / 08$.

47. —. 2001a "Working With Men For HIV Prevention and Care" UNAIDS Best Practice Collection, Geneva, UNAIDS

48. —. 2010. "Report on the Global AIDS Epidemic." Geneva, UNAIDS

49. - 2013. Gender Assessment of Rwanda's National HIV Response, Rwanda Biomedical Genter, Ministry of Health, http://www.rbc.gov.rw/IMG/pdf/gender_assessment_report_b5_f in.pdf 02/02/2015, Rwanda Biomedical centre. 2014, Rwanda Global AIDS Response Progress Report (GARPR) 2014

50. UNESCO, 2013,Addressing the links between gender-based violence and HIV in the Great Lakes region Workshop report, http://www.unesco.org/new/fileadmin/MULTIMEDIA/HQ/BSP/ GENDER/PDF/HIVGBVworkshopreport.pdf. 06/04/2015

51. USAID.2009. Integrating Multiple Gender Strategies to Improve HIV and AIDS Interventions: A Compendium of Programs in Africa, USAID, Washington DC

52. Wanyenze K. Rhoda K, Atuyambe Lynn, Kibirige Vista, Mbabazi Sarah, Tumwesigye M Nazarius, Djurhuus Kara and Namale Alice. 2011. "The new female condom (FC2) in Uganda:perceptions and experiences ofusers and their sexual partners", African Journal of AIDS Research, Vol.10. No.3: 219 $-224$

53. WhiteSarah.1997. "Men, masculinities and the politics of development", Gender and Development, Vol.5, No.2, 14-30.

54. Wilton Tasmin and Aggleton Peter. 1991."Condoms, coercion and control: heterosexuality and the limits to HIV/AIDS education". In P. Aggleton, P. Davies and G. Hart (eds) AIDS: Responses, Interventions and Care, Basingstoke: Falmer Press. 